\title{
Policy Decision Tree for Academic Digital Collections
}

\author{
Alexandros Koulouris ${ }^{1}$ 2, Sarantos Kapidakis² \\ ${ }^{1}$ Cetral Library, National Technical University of Athens, 9 Heroon Polytechniou str., 15773 \\ Polytechnioupoli Zografou, Athens, Greece \\ ${ }^{2}$ Laboratory on Digital Libraries and Electronic Publishing, Department of Archive and \\ Library Sciences, Ionian University, Plateia Eleftherias, Palaia Anaktora, 49100 Corfu, Greece \\ akoul@central.ntua.gr, sarantos@ionio.gr
}

\begin{abstract}
We present the results of a questionnaire survey for the access and reproduction policies of 67 digital collections in 34 libraries (national, academic, public, special etc) from 13 countries. We examine and analyze the above policies in relation to specific factors, such as, the acquisition method, copyright ownership, library type (national, academic, etc.), content creation (digitized, born-digital) and content type (audio, video, etc.); how these factors affect the policies of the examined digital collections. Responses were received from a range of library sectors but by far the best responses came from academic libraries, in which we focus. We extract policy (access, reproduction) rules and alternatives according to these factors that lead to a policy decision tree on digital information management for academic libraries. The resulting decision tree is based on a policy model; the model and tree are divided into two parts: for digitized and born-digital content.
\end{abstract}

\section{Introduction}

We propose a policy decision tree that contains flexible alternative access and reproduction policy solutions for digital information management in academic libraries. The decision tree is based on a conceptual policy model for digital information management, which is an evolvement and extension of our previous theoretical access and reproduction policy model for university digital collections [2]. The resulted decision tree may constitute a map or guide or policy pathfinder, for decision-makers and library managers in forming the policies (i.e. access, reproduction) and managing academic libraries' digital content.

\section{Findings}

We present the most important findings that were derived from the questionnaire survey and its data statistical analysis on collection level:

- The factors that mainly affect the access and reproduction policies are the acquisition method, the copyright ownership and the content creation type.

- Factors that affect less the previous policies are the content and library type. 
- The content creation type is independent from the library type.

- The library type diversifies the access policy structures (i.e. off-campus, offsite).

- Digital contents' acquisition method, especially in born-digital, diversifies access.

- Users' access diversification applies when other owners have the copyright.

- The libraries provide full off-campus onsite access for their own digital content, in which they have or administer the copyright.

- For the licensed content, and mostly for the born-digital, the libraries negotiate with the providers and they ensure remote access for their off-campus onsite users.

- When other owners have the digital contents' copyright, they restrict the full offcampus onsite access and they provide it in a limited sense.

- The libraries provide full offsite access for the digitized: library content, free thirdparty, public domain and licensed content; for the born-digital, they forbid it.

- In licensed content case, the provision of limited offsite access is widely used.

- The fact of copyright, especially when belongs to other owners, determines the kind of the (remote) offsite access (i.e. full, limited, or not provided).

- The user access rights' clustering ${ }^{1}$ depends on digital contents' acquisition method.

- For the library, free third-party and public domain digitized content, users' access clustering is not applied.

- In the case of licensed digitized content, either no, or common clustering is applied.

- For the purchased digital content, common clustering is applied.

- Common clustering applies in born-digital content case, independent of the acquisition method used. Especially for the purchased content, except the common, additional clustering is also applied.

- When the copyright belongs to other owners, usually common clustering is applied or rarely additional clustering may applied.

- The users' clustering is related with the, a) access diversification between onsite and offsite users, b) offsite, c) off-campus onsite and d) on-campus onsite access.

- Limited on-campus onsite access means additional clustering.

- The private reproduction is usually free, independent of library type, acquisition method and copyright ownership.

- Libraries prefer providing their content with free private reproduction, either with a credit (mention) to the source, or by applying fair use provisions, but usually without enforcing written permission and/or fee, or any other additional restriction.

- The commercial reproduction is usually not authorized; it is mainly permitted from other library types (i.e. profitable private libraries).

- In most of the cases where the commercial reproduction is permitted, written permission and/or fee are required.

- The copyright owner gives, except few cases, the written permission and takes the fee for the commercial reproduction.

- The written permission is not always accompanied by fee payment.

${ }^{1}$ In this research, we categorize (cluster) the users according to their access rights. The clustering may have the values: no, meaning that onsite and offsite users have the same access rights; common, meaning that there is diversified access between onsite and offsite users and/or between onsite users (on and off-campus); and additional, meaning that there is diversified access between on-campus onsite users, even if inside library premises. 


\section{Proposed Policy Decision Tree for Digital Information Management in Academic Libraries: Rules and Alternatives}

The rules and their alternatives that derived form the above findings result in a flexible (access and reproduction) policy decision tree, which is the core and proposal of this research. The decision tree is a policy route map, which offers alterative, flexible and effective access and reproduction policy solutions, according to the factors that apply on its case. It may have implications in building tools for making decision regarding policies and for managing the digital information.

The decision tree refers to the digital information life cycle focusing on its creation (digitized, born-digital), acquisition and availability (i.e. access, reproduction) without excluding its maintenance (preservation). It simplifies and unifies already used practices, and converts them to efficient policy rules. Additionally, it offers new, flexible, extensible and innovative policy alternatives (routes, paths).

The decision tree is divided into two parts, for the digitized and for the borndigital content separately, which are not included due to format constrains. However, the decision tree parts are incorporated in TR200701 technical report, available at http://dlib.ionio.gr/en/lab/treports.htm.

\subsection{Policy Decision Tree for Academic Libraries’ Digitized Content}

We analyze some representative examples of alternative proposed policy routes. Academic libraries may follow four available alternative options for their digitized content acquisition: library, third-party, public domain and licensed content. When library content is involved, the library digitizes the content available on its collections, in which it has or administers the copyright. The access is full and free for all users. Private and commercial reproduction should be permitted to all users with a credit to the source (i.e. content creator, provider) and with written permission from and fees paid to the library respectively.

When the library digitizes third-party content, the library administers the copyright, or other owners hold it, or library and other owners mutually administer (share) it, or finally, it may varies from item-to-item. When the library administers the copyright two access alternatives are proposed: full for all users, or full for onsite (on and off-campus) only and no (forbidden) for offsite. The private reproduction should be permitted with a credit (mention) to the source or by applying fair use doctrine. The commercial reproduction has two alternatives; its provision with written permission from and fees paid to the library, or its examination on case-by-case basis.

When other owners hold the third party digitized contents' copyright, the access should be provided to onsite users only; and not to offsite. In this case, only onsite users have the content reproducing privilege, with a credit to the source for private, and with written permission, given by the owner, for commercial reproduction.

Variant and alterative access and reproduction policy routes are proposed when the third-party digitized contents' copyright is shared among library and other owners or varies from item-to-item. For instance, in case of copyright sharing, the access is full for onsite and it is limited or not provided for offsite users. Finally, the licensed or public domain digitized content has other alternative policy proposals. 


\subsection{Policy Decision Tree for Academic Libraries’ Born-Digital Content}

Examples of alternative proposed policy routes are analyzed. Academic libraries may follow four proposing alternatives for their born-digital content acquisition: license, purchase, voluntary deposit and library content. When occurs to purchased borndigital content, other owners hold the copyright or library and other owners mutually administer it, or finally, it varies on item basis.

When other owners hold the copyright, the proposing access policy path is full oncampus, limited off-campus and no offsite. The private reproduction should be permitted with a credit to the source or under fair use provisions, and the commercial should not be authorized. Two additional alternative reproduction policy paths may be considered, when library and other owners mutually administer the copyright; the case-by-case examination (private and commercial) and the provision of commercial reproduction with written permission from and fees paid to the owners.

When the copyright varies from item-to-item (encountered in purchased borndigital content), three proposing alternative access policy paths may be selected: a) full on-campus, some off-campus and no offsite, b) full on and off-campus, some offsite (i.e. fig. 1), and c) full onsite and offsite. Proposing paths for reproduction are its provision by mentioning (credit) the source or by applying fair use doctrine (for private), and its forbiddance (for commercial).

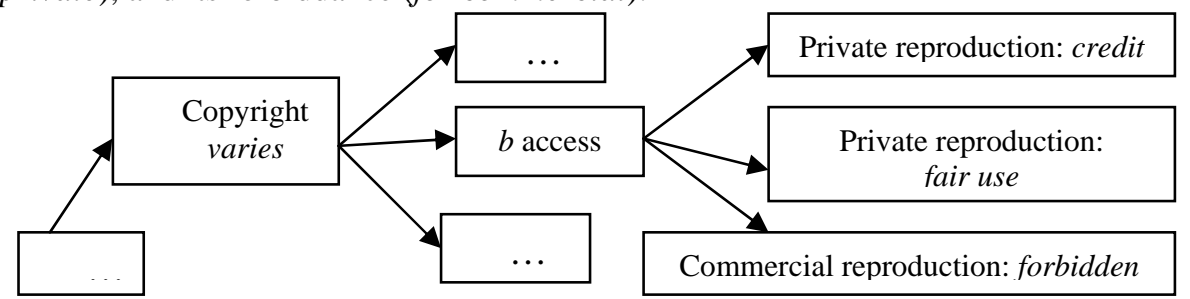

Fig. 1. Policy path examples of the decision tree for academic libraries' born-digital content

Academic libraries may alternatively select the voluntary deposit method for their born-digital content acquisition; having in mind that other owners control the copyright and normally impose policy (i.e. on access) restrictions. The proposing restrictive access (i.e. full on-campus, limited off-campus, no offsite) and reproduction (i.e. permitted for onsite users only) paths follow the logic of satisfying the content creators, and in accordance, ensuring the born-digital contents' voluntary deposit, viability and preservation.

\section{References}

1 Ayre, C., Muir, A. (2004) Right to Preserve? Copyright and licensing for digital preservation project Final Report, Department of Information Science, Loughborough University,http://www.lboro.ac.uk/departments/ls/disresearch/CLDP/DOCUMENTS/Final report.doc [Accessed 8-3-07].

2 Koulouris, A., Kapidakis, S. (2005) "Policy Model for University Digital Collections", Proceedings of the 9th European Conference on Research and Advanced Technology for Digital Libraries (ECDL 2005), Vienna, Austria, September 18-23, 2005 and Lecture Notes in Computer Science (LNCS), vol. 3652, pp. 356-367. 